\title{
Behavioral Approaches to Corporate Law
}

Donald C. Langevoort

Georgetown University Law Center, langevdc@law.georgetown.edu

Georgetown Public Law and Legal Theory Research Paper No. 12-055

Georgetown Business, Economics and Regulatory Law Research Paper No. 12-015

This paper can be downloaded free of charge from:

https://scholarship.law.georgetown.edu/facpub/909

http://ssrn.com/abstract=2042009

David C. Langevoort, Behavioral Approaches to Corporate Law, in RESEARCH HANDBOOK ON THE ECONOMICS OF CORPORATE LAW (Claire A. Hill and Brett H. McDonnell eds., Northampton, Mass.: Edward Elgar 2012)

This open-access article is brought to you by the Georgetown Law Library. Posted with permission of the author. Follow this and additional works at: https://scholarship.law.georgetown.edu/facpub

Part of the Behavioral Economics Commons, Business Organizations Law Commons, and the Securities Law Commons 
Behavioral Approaches to Corporate Law (forthcoming in Research Handbook on the Economics of Corporate Law, Claire A. Hill and Brett H. McDonnell eds., Edward Elgar, 2012)

\section{Donald C. Langevoort}

\section{INTRODUCTION}

In corporate legal scholarship, 'behavioral' analysis refers to using insights from psychology to address the relationships, rights and responsibilities among officers, directors, investors and other stakeholders. That does not make it a particularly welldefined subject. Psychology is a capacious field, running from the brain studies done by cognitive neuroscientists to the observations of interpersonal interactions in social cognition and social psychology laboratory experiments, the latter then bleeding into the separate field-study oriented research programs of sociology and cultural anthropology. In all these, there is so much - perhaps too much - for legal scholars to think about as potentially useful behavioral traits. Fortunately, researchers in business schools have for some time been using psychology as a tool for research specifically directed to organizational behavior and corporate governance, thereby giving legal scholars help in making connections of particular use to the analysis of corporate law-related issues (Camerer \& Malmendier 2007).

My contribution reflects on the challenges of making these connections and some of the successes that have occurred so far. I make no effort to provide a thorough literature review - the number of published articles and works in progress that plausibly 
fall into the 'behavioral corporate law' category is sizable, and grows rapidly each year. The amount of contemporary scholarship in business, finance and economics that turns to psychology for insight relating to business institutions, from which legal research can then draw, is much larger.

What I want to outline here is an approach to using psychology for corporate legal analysis that addresses the obvious question: if persons (and presumably firms) are capable of acting rationally and have strong market-driven incentives to do so, why will that not drive out the irrational from having influence in a competitive marketplace? A plausible answer comes only if agents simply cannot act more rationally than their competitors or - more likely, in my view - there is something competitively adaptive about the particular heuristic or bias in question in business settings (which, of course, makes it unwise to label it 'irrational'). After exploring this question generally, I will turn to two subject areas to which behavioral corporate law scholarship has paid particular attention - the group behavior of corporate boards of directors, and the so-called 'inefficient markets' hypothesis that is the subject of modern behavioral finance. I conclude by briefly considering the relationship between psychology and culture, extending the approach put forth here to the place of corporate culture in legal analysis.

\section{[a] THE BEHAVIORAL TURN}

The 'behavioral' move in corporate and securities law scholarship is largely critical and reactive. Beginning largely with the seminal work of Henry Manne (1966) and continuing through a scholarly revolution in the 1970s that to this day still frames the scholarly enterprise of corporate legal research, the methodological assumptions of orthodox financial economics - individual rationality and market efficiency - came to 
dominate. This led to conclusions that, more often than not, criticized existing legal constraints as unnecessary or inefficient, and offered a deregulatory normative agenda in place of the legal status quo.

Critics of extensive reliance on these methodological assumptions, in corporate law and elsewhere, naturally turned to psychology to take aim at the rational actor paradigm. If people often predictably behave irrationally, then maybe these strongly deregulatory normative conclusions are unfounded. From the outset, however, this effort had trouble gaining traction because of a fairly obvious set of problems, with which the behavioral approach has struggled ever since. So-called ‘irrationality’ (or even bounded rationality) is hardly automatic or universal - the evidence we observe in the laboratory and the field varies considerably among the population, is highly situational and contingent, and institutionally constrained. That is to say, we observe a variable mix of rationality and suboptimal judgment and decision-making in our society and economy. And thus the orthodox economists can readily concede the irrationality of some people without in any way jeopardizing the basics conclusions of financial economics. Competitive markets reward rationality and penalize irrationality, they say, so that the cognitively weak should disappear from significance and institutions should develop to protect against bias. So long as arbitrage is possible in market settings, moreover, irrationality will not generate even short-term distortions, because any irrational price movements will immediately be exploited by the rational behavior of the so-called smart money, driving the price back to the rational expectations value. Richard Posner (1998), Roberta Romano (1986) and others have famously doubted the value of behavioral economics in business settings on grounds like these. 
They are right to a point. For example, consider the challenge faced by an academic who wants to claim that because of some predictable behavioral or cognitive biases familiar in the psychology literature, corporate chief financial officers are likely to act in a certain legally problematic fashion. For this inference to be well-grounded, at least each of the following would have to be true:

(1) the bias in question would have to be shown by researchers to be a commonly occurring phenomenon in the general population (not just an artifact of experimental design);

(2) people who become CFOs would have to be at least as prone to the bias in question as the population that was studied in the experimental setting;

(3) to the extent that the bias in question is situational or contingent, the setting in which the CFO makes the decisions would have to generate the right kinds of triggers;

(4) the setting would not involve the kind of repeat play from which the CFO (maybe before she took on that role) would learn from experience so as to avoid these biases; and (5) the institutional environment in which these decisions are made would contain no 'debiasing' constraints, such as off-setting contractual incentives, peer review, external monitoring or structured group deliberation.[/numbered list]

Usually, this will be hard to show. Among other things, CFOs - or CEOs, board members, portfolio managers, etc. - are not randomly drawn from the general population. Rather, they are survivors of high pressure employment and promotion tournaments that almost always took a significant degree of cognitive skill to win. Unless there is reason to believe that irrational bias could survive such a tournament, its presence among decisionmakers at the top cannot be presumed. Moreover, the institutional incentive for firms to 
de-bias is well-recognized, as is the ability of institutional context to cue the pursuit of rational self-interest (Heath 1998; Arlen et al. 2002).

An inference of bias is questionable, then, but by no means impossible. There likely are cognitive biases that are adaptive enough in competitive settings to survive. For example, overconfidence and mildly inflated self-esteem (ego) are associated with greater risk tolerance, ambition, persistence and a host of other useful traits in a business environment (Goel \& Thakor 2008; Malmendier \& Tate 2008a, 2008b; Langevoort 1997). Here we see the interaction between luck and skill that is so important in psychology (fundamental attribution error, etc.) - many high-achieving individuals overattribute success to skill, and put out of mind the situational randomness that sometimes generates good fortune. The overconfident may 'play’ harder and more aggressively, producing more extreme positive and negative outcomes. Those lucky enough to get the positive outcome may play even harder and more aggressively the next round. If there are enough players in the tournament, there will be a lucky few who are rewarded repeatedly, more than their more realistic, conservative peers. So overconfidence could be highly adaptive, and if so we might expect CEOs to exhibit that particular bias (though whether that bias would persist after they have won the tournament and now are motivated to protect their status is itself open to question). We can imagine other adaptive traits as well. For example, the sunk cost bias - investing 'irrationally' after an earlier commitment to a choice - may relate closely enough to valued, observable consistency traits that it survives in repeat play. Or 'quick and dirty' heuristics that lead to good choices most of the time will produce quicker, more nimble behavior compared to the 
manager who (realistically) worries at length through every problem (Gigerenzer \& Selten 2001).

To know whether cognitive and behavioral biases do affect judgment and decision-making in business settings, then, we cannot simply point to the existence of the bias in the general population and then assume that it automatically applies to any given business context - on the other hand, nor can we rule out its presence simply because of the marketplace. Fortunately, behavioral researchers in business schools have made substantial progress in addressing the problem through a number of strategies. One is to use experienced business people as subjects in laboratory experiments, to test for persistent 'expert' biases. Another is the increasing use of field studies looking at real decisions in economic settings (DellaVigna 2009). If we find on-the-ground evidence of suboptimal choice, researchers can then try to match the observations with theories of bias to find the best fit.

We can illustrate both the promise and challenges of using insights from psychology in corporate and securities law by looking at a recent legal controversy: the behavior of sell-side securities analysts, who advise brokerage firm customers and others about investment opportunities (Fisch \& Sale 2003). Well before the scandals of the early 2000s, financial economists had found evidence that favorable recommendations significantly outnumbered unfavorable ones, especially with respect to issuers who were or might become investment banking clients of the analysts' employer. The standard economic account was one of deliberate skewing of recommendations because of the conflict of interest, which became the regulator's charge as well, and the basis for subsequent regulatory reform. 
A competing explanation, however, is behavioral: that analysts with a good faith optimistic bias (i.e., true-believers, say, in the future of a particular technology in which the issuers they cover are heavily invested) are favored for a variety of reasons. For instance, issuers prefer them and thus provide them with superior access to information; they generate more retail commission business because of their infectious enthusiasm; they are willing to take greater risks in their recommendations and hence gain the halo of positive association for major strokes of luck, etc. The conflict of interest is not irrelevant, because it is part of the institutional environment that causes the optimists to be so favored. But the process by which the optimists thrive is natural selection, not (necessarily) savvy opportunism.

Economists might ask: so what? Outcomes are important, not motivations, and the outcomes arguably appear consistent with rational choice. But in the law, state of mind is usually crucial, with the standard varying depending on the legal rule invoked. Reliance on fraud-based prohibitions - as federal regulators did in the analyst cases - would be ineffective as applied to the true optimists. On the other hand, there would be the risk of unfair liability under a scienter-based regime if judges and juries disbelieve their good faith defenses based on a naively cynical assessment of their motivations. The difference would also be important in fashioning cures for the bias. For example, a certification that the analyst is being honest in her recommendation - as now required by SEC Regulation A-C - might work with respect to deliberate bias but be largely meaningless with respect to those simply prone to over-optimism.

One of the 'cures' for analyst bias - extended to many other settings as well as a result of recurrent financial scandals - is strengthened disclosure of conflicts of interest. 
Will this work? An interesting finding from psychological research is that persons who disclose conflicts may actually feel freer to act selfishly, because the disclosure gives them moral license by warning the counterparties of the risk (Cain et al. 2005). On the other hand, subsequent research has pointed out that in laboratory settings where there is repeat play and hence greater opportunities for those hurt by the selfishness to punish it later on, the opportunism diminishes (Church \& Kuang 2009; Koch \& Schmidt 2010). Given the stress placed in corporate and securities law on disclosure, understanding this dynamic more fully seems crucial to developing a coherent regulatory response to the problems of pervasive conflicts not only on the part of analysts but of many different kinds of economic actors.

All this, of course, simply emphasizes the need for corporate legal scholars to build their normative arguments on a solid base of empirical observation - preferably in the field - rather than simple borrowing from laboratory research in psychology generally. When some form of suboptimal decision-making is identified in practice, then the task turns to explaining why. As in the analyst context, it will often be the case that multiple behavioral and rational (e.g., agency cost) explanations are plausible, and again, it may be tempting to choose the more parsimonious rational explanation for purposes of legal analysis. But even putting aside the importance of inquiry into state of mind as a matter of law within that analysis, this can be dangerous. Imagine that we estimated that the likelihood of the behavioral effect being important is only 25\%. If the regulatory intervention would fail because it ignores that effect even in a relatively small number of instances, the aggregate cost - the legal risk - might still be material. Simply assuming rationality because that is the best available description of behavior ignores the ecological 
diversity of outcomes in judgment and decision-making in social and economic settings, and hence the risk embedded in the broad societal 'portfolio' of choices.

\section{CORPORATE BOARDS: LOYALTY AND 'STRUCTURAL BIAS'}

As modern corporate law developed, it has emphasized the adequacy of decision-making process over review of substantive outcomes. This is a natural response to the diversity of situations that challenge a corporate entity at any given time, and the need for flexibility, risk taking, etc., as well as the institutional incapacity of courts to second-guess business decisions particularly well. By and large, except in the case of the most severe conflicts, the key has been 'independence’ (or ‘disinterestedness') - so long as a sufficiently independent decision-maker within the approved corporate hierarchy has been given all the material facts and approved some action after due deliberation, the action is beyond serious judicial review. To this end, many contemporary corporate governance initiatives under both federal and state law seek to force greater independent director involvement at key decision points, and ex post judicial inquiry into independence can sometimes be quite robust.

Independence, however, is a fuzzy concept, and the temptation has long been to objectify the legal standard - independence is simply the absence of a certain level of self-interest in the outcome of the decision itself. To be sure, such an interest can take any number of forms but it remains focused largely on status or financial interest. This led to an outpouring of criticism from legal scholars using psychology research to call into question whether standards so based can reasonably assure the kind of objectivity that 
eliminates the need for judicial review of sensitive corporate decisions. The classic work by James Cox and Harvey Munsinger (1984) on judicial review of special litigation committee decisions recommending termination of a derivative lawsuit because of 'structural bias' was particularly influential, at least in academic circles (see also Hill \& McDonnell 2007). Others are more willing to accept the desirability (or inevitability) of limited judicial review but then push for structural corporate governance reforms to create a better chance of independence ex ante. These, too, often invoke something from the psychology literature as justification.

An interesting example of the latter is the argument by Randall Morck (2008) in favor of separating the chair and CEO functions in corporate governance. His claim is that directors are psychologically susceptible to the kind of 'obedience' commands submission to authority - demonstrated in the classic social psychology experiments by Stanley Milgram (1974). Hence the excessive deference to CEO influence, which could be counterbalanced by introducing a separate, equal authority figure in the person of the non-executive board chair.

This is a nice illustration of both the potential benefits and the challenges associated with psychology-based analysis of corporate legal issues. The Milgram results have been widely replicated, and are robust to a number of modifications to the original experimental design. But does the relationship between a CEO and other board members resemble closely enough the relationship between the 'teacher' and the experimental subjects? After all, especially in larger companies, independent board members are recruited based on their prior history of success in other endeavors, and are likely to be 
high-status, high self-esteem individuals. That they are prone simply to do what they are told by the CEO is doubtful.

Morck does offer some other psychological tendencies that might reinforce the deference to insider authority. For example, the inclination toward reciprocity might cause board members to defer - consciously or not - out of gratitude for the invitation to join the board and the perquisites of membership. Or in-group/out-group biases might cause board members to reject externally generated threats directed at others on the board ‘team', especially if the board has developed a fairly close working relationship. These are somewhat more plausible as an explanation for excessive deference, but still seem incomplete: after all, we know that deference has its limits (boards do challenge and fire CEO’s with increasing frequency) and these tendencies would not have much explanatory power as to the circumstances under which deference diminishes.

There is probably a deeper, more subtle cognitive dimension to excessive deference (see, e.g., Langevoort 2004). Businesses tend to be very complex, opaque and dynamic. The task of understanding any business deeply is perhaps beyond any person's capacity, even the company’s senior executives. Outside directors come to the task with woefully little information of their own, and are highly dependent on a combination of reports generated (and controlled) by insiders and external cues such as press coverage and stock prices. This profound ambiguity suggests that key decisions - is the CEO doing a good job, how much should we pay her, etc. - will be made without a high degree of confidence, which leads naturally toward preserving the status quo. Absent real evidence of a problem, no director wants to throw a monkey wrench into the functioning corporate machinery where raising issues (for example, suggesting a leadership change or calling 
into question some corporate investment) might end up hurting rather than helping - nor does he or she want to display embarrassing ignorance by entering into a losing argument with someone far more familiar with the facts on the ground.

Other psychological tendencies can bolster this. When nothing is said or done to question some course of action, it becomes even harder to change later on. Commitment and sunk cost biases (cognitive dissonance, perhaps) make it hard to perceive or acknowledge that there is enough different to justify a reversal. And if individuals stay silent as a result, others on the board can easily interpret the silence as a signal that nothing is amiss, amplifying the status quo bias through a form of social proof. At the group level, this may take on the familiar form of 'groupthink' (Benabou 2009; O’Connor 2003). And to the extent that independent directors are drawn from the ranks of either current or former business executives, their natural frame is to see things in ways sympathetic to the challenges facing management (Hill \& McDonnell 2007).

My point is simply that evidence of excessive deference is not necessarily the product of motivational influences like submission to authority or excessive loyalty. And this is important when we turn to proposed cures like separating the roles of CEO and board chair. Simply introducing a competing authority figure in the board setting does little to remedy information deficits or resolve ambiguity, unless that role is substantially empowered with full-time staff and other forms of support - which is bound to introduce a very different dynamic, and not necessarily in the direction of greater operational efficiency.

Morck acknowledges that the empirical evidence has not demonstrated any clearcut benefits to separating the roles of CEO and board chair, which casts doubt on the 
simple Milgram hypothesis. His main interpretation, however, is that the authority of the CEO is too strong to be countered by simple separation, and that additional steps may be needed, like giving institutional shareholders greater nominating and election rights so as to create a more direct line of responsibility between independent board members and their constituents. While that may or may not be wise for a variety of other reasons, more powerful shareholder suffrage offers no solution to the informational problem, and might bring into the boardroom different heuristics, but not necessarily better ones. If - as many commentators have suggested - independent directors are particularly influenced by the stock price as the best test of managerial performance, then we might find greater pressure to do what the market values as opposed to what the company's own private stock of information would suggest. Or we might see more mimetic behavior as management fads and fashions spread through the empowered director community. Morck notes these risks, but suggests that this is the only way to stimulate open debate and questioning in the face of the CEO's overwhelming psychological authority.

While I am convinced that excessive deference at the board level is less about loyalty and subservience than many think, I think we may understate their significance as applied to executive behavior. To be sure, Milgram-like submission can readily be expected among subordinates in the corporate hierarchy. Key to the development of a strong, positive corporate culture is a willingness to sacrifice for the good of the team. Strong leaders build such teamwork by modeling the behavior themselves, and one can reasonably suspect that the best leaders take on the ethic of group care fairly naturally. To be sure, they may demand the outsized compensation package at a rate suitable for being the 'boss', but accepting that their loyalty must be commensurate. 
In law, we are used to thinking about CEOs as self-aggrandizers, and hence the duty of loyalty is generally thought of in terms of conflicts between personal utility and shareholder wealth. It would not surprise me, however, if loyalty to other members of the team - fellow executives, valued assistants, and the like - was a strong driver of senior executive behavior. One of the important puzzles in corporate and securities law is why executives so often lie, putting at risk their reputations, wealth and sometimes, freedom. No doubt there are many possible explanations, but one could well be a willingness to 'take one for the team', trying to save the organization from competitive failure even if it takes violating the law to do so. Imagine, for example, Ken Lay of Enron, convicted of lying during the last stages of the company's deceptions when he returned to the role of CEO after some time away. By all accounts, the bulk of the fraud was engineered by others, mostly during Lay's absence. So assuming upon his return he discovered the fully contrived fraud, why not blow the whistle on it? My sense is that strong multi-directional loyalty is a big part of the explanation, because blowing the whistle would cause immediate and catastrophic harm to many people inside the corporate family, many of whom were not particularly guilty of any wrongdoing, and who had been very loyal to him. To avoid this harm to others, he might have been willing to try to continue the deception long enough to extract the company from it, at considerable personal risk.

A deeper understanding of loyalty inside the corporation is important for corporate law. If there are pathologies of loyalty, this would be important to the design of internal controls, which use motivational assessments as indicators for where resources are most needed. More generally from an academic perspective, it raises an interesting and underappreciated point about human behavior in economic settings: that some of 
what we regard as troubling conduct in terms of harm to certain stakeholders (e.g., harm to investors) is often other-regarding behavior vis-à-vis a different set of stakeholders. And that other-regarding behavior - organizational loyalty - is very functional and valuable most of the time, even for investors. Like intra-organizational trust (see Hill \& O’Hara 2007), it is not something that investors should want to diminish appreciably, even if it has its risks.

\section{BEHAVIORAL FINANCE AND INVESTOR PSYCHOLOGY}

The academic subspecialty of behavioral finance uses insights from cognitive and social psychology to analyze the behavior of investors, both in terms of individual investor decision-making and price formation in organized markets as a result of the interaction among many investors. The latter field responds to the prevalent assumption throughout most of the last four decades that organized markets are efficient, i.e., that stock prices are an unbiased estimate of value into which new information is promptly impounded. The empirical evidence about stock prices does not fit this paradigm particularly well, leading many financial economists to try to explain regularities in price movements, like momentum effects and investor over-reaction or under-reaction to particular kinds of news, by reference to psychological heuristics and biases (Baker et al. 2007). This effort relates back to Keynes' famous assumption that 'animal spirits' are deeply at work in the securities markets, which has become a well-worn cultural trope (Langevoort 2002). 
'Noise trading' is the preferred description of non-rational activity that has the potential to affect market prices. ${ }^{1}$

Economists’ work in behavioral finance divides into two main branches. One takes investor sentiment as an important driver of stock market prices, which rational managers exploit by timing important corporate transactions (issuances of new securities, repurchases, corporate takeovers) strategically. The other considers the possibility that managers are biased as well, so that investor and executive biases interact.

Given the role that market prices and efficiency-based theories have played in corporate law and economics over the last decades, this is an important body of research for corporate legal scholars. As Reinier Kraakman (1988) noted some time ago, optimal legal policy toward corporate takeovers rests heavily on one's assessment of whether a takeover bid necessarily rests on the bidder's (presumably rational) belief that it can add value to the target, thereby justifying the premium, or whether instead the bidder may simply be 'cherry-picking' a sentiment-driven drop in market value. Using market price as the best measure of managerial performance becomes increasingly risky as doubts about efficiency grow. The financial scandals - Enron and Worldcom in the early 2000s, in financial services more recently - have fueled fears that market prices can become a dangerous obsession, which the law should lean against (Stout 2003).

Behavioral finance needs to be used gingerly, because it remains a controversial subject and has not generated a tractable model of stock price behavior to substitute for the efficient market hypothesis. The general evolution of financial markets may well be toward efficiency, even if imperfections are readily observable right now, and the point is

\footnotetext{
${ }^{1}$ For further discussion of behavioral finance in this volume, see Cunningham (Ch. 16) and Gilson and Kraakman (Ch. 24).
} 
often made that behavioralists have not yet found investment strategies that produce supra-normal returns on a sustained basis. Normatively, it is not altogether clear that the presence of noise traders is problematic - they may simply be providing the liquidity that justifies investment by the smart money into the research that, in turn, moves stock prices toward more efficient levels. Moreover, the kinds of policy moves that seem logical as faith in markets prices diminishes - especially greater regulatory intervention - turn on the question of whether regulators are any less subject to cognitive bias or otherwise capable of improving on market-based results, even assuming the market is prone to mood swings.

Since the 1980s, corporate legal scholars have struggled with how to deal with empirical doubts about the strength of market efficiency. The obvious and important line of work is to identify those places in law or legal scholarship where efficiency has strongly been assumed, and show the risks associated with implementing legal norms that depend on the accuracy of that assumption and the consequences if that assumption is indeed misplaced. However, at least in law (as opposed to scholarship), strong claims of market efficiency are not necessarily essential to many of the rules that invoke the rhetoric of efficiency.

A good example of this - generating a great deal of unnecessary confusion in both law and scholarship - involves fraud-on-the-market litigation under the federal securities laws. Famously, in Basic Inc. v. Levinson (1988), ${ }^{2}$ the Supreme Court embraced market efficiency in recognizing a presumption of reliance on market price integrity (and in dissent, Justice White criticized the embrace as too passionate given the lingering

\footnotetext{
${ }^{2}$ Basic Inc. v. Levinson, 485 U.S. 224 (1988).
} 
empirical doubts). Though seen today largely as a generous gift by the Court to private investor plaintiffs and their lawyers, that presumption was strongly urged at the time by notable conservatives, particularly Frank Easterbrook and Dan Fischel (1985). They strongly believed that markets were efficient, and that by making market price distortion the test for materiality, reliance and causation in these lawsuits - measured by econometric evidence - greater rigor and discipline would be imposed on this otherwise unruly litigation.

As a result, courts after Basic gradually came to assume that the presumption of reliance could only be justified if the market was in fact efficient (Langevoort 2009). So, as doubts about efficiency grew in the behavioral finance literature (Brav \& Heaton 2003) and were voiced in the course of litigation by expert witnesses, court began more aggressively to dismiss cases where efficiency was seriously put into question (i.e., for less widely traded securities). And they were forced to confront troubling questions about apparent inefficiencies even with respect to the biggest blue chip issuers. In the legal academic literature, more and more scholars invoked the behavioral finance research to suggest the need for a fundamental rethinking - if not outright abolition - of the fraud on the market presumption.

Given the language and reasoning in Basic and its progeny, this move seems to make sense. But if we think harder about the question, it is far from clear that it should. The presumption of reliance is essentially the creation of an entitlement to rely on the integrity of a stock's price even when any reasonable investor would have to admit that prices lack integrity with enough frequency that simply assuming integrity is foolish. Like the common law of fraud, it facilitates reliance and thus promotes capital formation 
by lowering the risk of investing. Nothing in that idea requires any assumption about market price, and it would be as well justified as applied to a relatively unknown mid-cap issuer as a blue chip stock.

The connection to market efficiency here is simply that the primary econometric tool used to test for and measure marketplace distortions - the event study, measuring the abnormal returns in the aftermath of corrective disclosure by the issuer - derives its power and elegance from assumptions about efficiency. But as Macey et al. (1991) showed in an important article shortly after Basic, the event study has sufficient power even when a market is well short of ideal. The level of confidence diminishes as volatility increases, but not so much as to render the event study unusable to make probabilistic assessments, and many kinds of fraud will generate dramatic enough price distortions that there simply is no close question at all. As they conclude, the fraud on the market suit need not strictly be limited at all to those markets that evidence very high levels of efficiency.

So why has the law (and the academic literature) so confidently marched in the other direction? An important shift in thinking about the fraud on the market lawsuit has been toward doubting its efficacy, because of concerns about the incentives of plaintiffs' attorneys as well as the frustrations about the costs of litigation. Other countries - gaining competitively on the United States in capital markets activity - have nothing comparable as a compensatory vehicle, raising further questions about the balance of costs and benefits. In this setting, judicial and academic doubts about the efficacy of private securities litigation make it tempting to seize on questions about efficiency as a reason to 
resolve disputes against plaintiffs. Efficiency itself is neither necessary nor sufficient to this analysis, but offers rhetorical camouflage given its starring role in Basic.

My sense is that strong assumptions about marketplace efficiency in the law are often more about rent-seeking than empiricism. In the aftermath of the financial crisis that began in 2007, much has been said about the 'error' of thinking that markets were sufficiently self-disciplining and self-correcting that the regulation of financial institutions could take on a fairly light touch. But aside from some academic literature, it is far from clear how much policy was based on a bona fide belief in that. Mainstream work in financial economics, especially of the new institutional variety, has for some time emphasized informational imperfections, agency costs and moral hazards that interfere with optimal outcomes as measured in terms of either shareholder or societal interests. The behavioral literature added other reasons for skepticism. Bubbles, crashes and scandals repeatedly in the last two decades offered ample evidence of marketplace shortcomings. In the face of all this, such a bona fide belief would be nailve.

More likely, the rhetoric of the self-disciplining market was simply intended for external consumption as a means for achieving the preferred deregulatory outcome. One form of this is pure rent-seeking, but it need not be only that. Those with a bona fide skepticism of government intervention in markets have the incentive to overstate the market's capacity for self-cleansing - and to deny the human imperfections embedded in markets - to counter or diffuse political demands for heavier regulation. Perhaps they repeated it so much that they came to believe their own rhetoric, but my guess is that few proponents of deregulation seriously thought that markets work quite so perfectly. 
The financial crisis should thus offer a boost to behavioral corporate and securities law. Understanding with greater precision why markets, firms and individuals made risky choices that they came to regret is the task at hand. As just suggested, many of the possible answers have nothing to do with psychology - these could have been rational choices (though perhaps self-serving ones for firm agents) under conditions of severe informational ambiguity. But behavioral explanations are likely candidates as well (Avgouleas 2009; Miller \& Rosenfeld 2010; but see Posner 2009).

For example, investor sentiment might well have favored market leadership in the emerging 'shadow banking' sector and portfolio managers might have been reluctant to bet against that sentiment continuing, reducing the amount of arbitrage activity. Inside the firms, the kinds of biases discussed earlier (over-optimism, etc.) could have paid off handsomely in the short run, leading to the promotion of the more biased compared to the less, with an obvious effect on the internal culture. This is important, of course, because competition is so central to corporate economic activity, and by most accounts, increasing in most industries because of technology, globalization and the like. If competition induces - or favors - a particular mindset, producing judgment at odds with dispassionate rationality, then the law's efforts to respond with a fine-tuned set of rational incentives or disincentives will surely miss the mark. Nor will it be particularly easy to intervene by shifting greater responsibility to third-party actors (e.g., directors on an audit committee, accountants, lawyers), even though the benefits of involvement in risky decisions by the non-euphoric seem clear. There will be disagreement about the perception of risk that will turn conversations into power struggles, and unless the third-party actors have sufficient information at their disposal to hold their own in that struggle, the risk-seeking 
culture is likely to prevail in those struggles. The challenge for the law - and for the institutions of corporate governance - is to find steps toward detoxification without disabling the firm in the process.

\section{FROM PSYCHOLOGY TO CULTURE}

Behavioral corporate law scholarship is generally viewed in distinction to the corporate law scholarship that uses the assumptions of conventional economic analysis. But a separate challenge comes from sociology, where there has been a long-standing skepticism about the methodological individualism in both psychology and economics. This is especially so when the subject of analysis is institutional. Thus, in management studies, there is a strong view of organizational behavior that rejects any substantial focus on individual actors, instead attending to the diffusion of norms and perceptions inside the firm as a matter of social construction (Weick 1995; Brown 1997). This critique is often anti-functionalist, rejecting the idea - dear to economists both orthodox and behavioral - that heuristics and norms develop and persist only to the extent that they serve a useful purpose.

As always, this controversy can be judged only by reference to empirical observation. My suspicion is that the economists have the better of the argument - it is hard to look at a successful business firm and believe that all is just myth, ceremony and mimetic diffusion of randomly generated beliefs - but that debate is beyond the scope of this article. What corporate legal scholars should find interesting and useful is that social constructs like culture can be examined through the lens of behavioral (as well as 
orthodox) economics in ways that respond to the sociologists' complaint about excessive individualism, while at the same time remaining faithful to a functionalist perspective. An important example of this, noted earlier, is the analysis by Akerlof and Kranton (2005) of organizational cultures that stress extreme loyalty, e.g., the US Marine Corps, showing that by conferring a strong sense of identity, such cultures are functional mechanisms for overcoming the temptation to defect in the face of danger, which is essential for group survival.

By and large, studies of organizational culture are about sense-making in the face of ambiguity, and the diffusion of beliefs among organizational stakeholders. Reality is not some exogenous state of affairs, just widespread social construal. If one then adds an insistence on some degree of functionalism for survival in a competitive market, it follows that cultural norms and beliefs will persist over time only to the extent that they are useful. Here we can build on the basic idea in the previous sections: there are certain kinds of beliefs that are adaptive in a competitive setting regardless of whether they are precisely accurate (e.g., over-optimism).

Consider corporate cultures generally. The basic challenge facing any organization is one of coordination: the interaction among multiple corporate agents will be unproductive to the extent that there are endless negotiations over what is happening, why and what is best now to do. Organizational hierarchies can try to impose order from above, but that is unlikely to be effective unless agents actually come to hold common beliefs. An organization that develops a common culture on matters relating to 'what', 'why' and 'should' will operate more efficiently in the short run and thus be more competitive than those that do not (Kreps 1990). 
From this perspective, it is not hard to predict some of the substantive content of particularly productive corporate cultures (Langevoort 2006). Optimism and group selfefficacy are likely to be adaptive by enlarging the apparent pool of future rewards from cooperation. The simplification of perceptions of reality, rather than its complication, will also facilitate the coordination function - simple sense-making stories are more effective at allowing agents to get on with their business than complicated, ambiguous accounts. The problem, of course, is that as perceptions cohere in a way that promotes nimbleness and productivity, there may be a resistance to external signals that are inconsistent with prevailing beliefs. Risks, ethical challenges and the like are ruled out of order because they burden the negotiation of reality.

The relevance to legal analysis is thus clear. Legal scholars are used to discussing corporate cultures as either benign or corrupt, implicitly assuming that reality is well perceived so that the only remaining distinction reflects agency costs: the culture either promotes good ethics and law-abidingness or not. Taking culture seriously means accepting that reality is relative, and that unrealistic beliefs that are functional in the short run will not easily be challenged by outsiders.

There are a number of legal implications. One, relating back to the earlier discussion of state of mind, suggests that the notion of 'corporate scienter' is likely to be very difficult to assess - internally, firms may have ways of assessing information that is entirely genuine and in good faith, but unrealistic. Should a firm that trivializes risk in some corporate publicity or SEC filing bear liability under an intent-based legal regime upon a finding that the risk would have been palpable to an external observer? If the 
answer is no, the credibility of that disclosure drops considerably. But if the answer is yes, we are talking about liability for something other than corporate bad faith.

So, too, with corporate governance. One of the better arguments for enhanced shareholder suffrage rights is that firms can become captive to cultures that ignore change in the environment - indeed, an important line of thinking on organizational ecology is that most all firms eventually die because they lost the capacity to change as a result of the hardening of internal processes and beliefs. If one believes - admittedly it is far from clear - that institutional investors have a better capacity to perceive the need for a company to shift direction, then stronger outsider influence would be desirable. On the other hand, if corporate cultures are indeed so powerful, they will resist intervention from the top. The goal then is to find mechanisms of corporate governance that allow the reality that might be brought to bear by outside directors and others to seep into the culture slowly enough that it doesn't render it unable to do the essential work of simplification and coordination. This, for example, might be an argument for requiring as some best practices are starting to encourage - more regular meetings and discussions directly between the independent directors and key managers (on matters of risk management, compliance, etc.), rather than allowing the CEO to define and control those interactions.

\section{CONCLUSION}

Psychology offers useful insights to corporate law scholars in situations where the particular trait or tendency in question is empirically robust, situationally plausible, and 
either so hard-wired into the human brain that it will operate even in the face of substantial institutional constraints and disincentives or - better yet - actually be functional and adaptive in the marketplace. On both the individual and cultural level, it is not hard to identify traits and tendencies that might satisfy this test even though the behavior in question does not satisfy the formal demands of Bayesean rationality.

So stated, the apparent tension between psychology and economics diminishes considerably. New institutional economics has been more than willing to embrace psychology in the study of intra-firm behavior, for example. And behavioral finance has become important enough that the most respected journals in financial economics contain multiple contributions from this genre in nearly every issue. Again, the key is a plausible theory of frequency, adaptation and persistence.

Of these, frequency is probably the hardest, and something that can only be addressed empirically. Savvy behavior is commonplace, and evidence of the 'opportunism with guile' that describes the conventional economic approach is ample. For all the plausibility of the role of psychology in the recent financial crisis, for example, moral hazard and agency cost problems offer plausible explanations for what we observed, too. The task for corporate law scholarship in situations like these is to disentangle the rational from the biased to the greatest extent possible, and assess the efficacy of our toolkit of legal strategies in light of the resulting mix. Realistic approaches to corporate governance, regulation and liability depend on how well that assessment is done. 


\section{REFERENCES}

Akerlof, George \& Rachel Kranton (2005) 'Identity and the Economics of

Organizations', Journal of Economic Perspectives, 19, 9-32.

Arlen, Jennifer, Matthew Spitzer \& Eric Talley (2002) 'Endowment Effects Within Corporate Agency Relationships’, Journal of Legal Studies, 31, 1-37.

Avgouleas, Emilios (2009) 'The Global Financial Crisis, Behavioural Finance and

Financial Regulation: In Search of a New Orthodoxy’, Journal of Corporate Legal Studies, 9, 121-57.

Baker, Malcolm, Robert Ruback \& Jeffrey Wurgler (2007) 'Behavioral Corporate Finance: A Survey', in B. Espen Eckbo (ed.) The Handbook of Corporate Finance: Empirical Corporate Finance, Amsterdam: Elseiver/North Holland, 145-89.

Benabou, Roland (2009) ‘Groupthink: Collective Delusions in Organizations and Markets’, National Bureau of Economic Research Working Paper w14764.

Brav, Alon \& J.B. Heaton (2003) 'Market Indeterminacy’, Journal of Corporation Law, 28, 517-39.

Brown, Andrew (1997) 'Narcissism, Identity and Legitimacy’, Academy of Management Review, 22, 643-86. 
Cain, Dylan, George Loewenstein \& Daniel Moore (2005) 'The Dirt on Coming Clean: Perverse Effects of Disclosing Conflicts of Interest', Journal of Legal Studies, 34, 1-25.

Camerer, Colin \& Ulrike Malmendier (2007) 'Behavioral Economics of Organizations’, in P. Diamond and H. Vartanian (eds) Behavioral Economics and its Applications, Princeton: Princeton University Press, 235-90.

Church, Bryan \& Xi Kuang (2009) ‘Conflicts of Interest, Disclosure and (Costly) Sanctions: Experimental Evidence', Journal of Legal Studies, 38, 505-32.

Cox, James \& Harvey Munsinger (1984) 'Bias in the Boardroom: Psychological Foundations and Legal Implications of Corporate Cohesion', Law and Contemporary Problems, 48, 83-135.

DellaVigna, Stefano (2009) 'Psychology and Economics: Evidence from the Field', Journal of Economic Literature, 47, 315-72.

Easterbrook, Frank \& Daniel Fischel (1985) 'Optimal Damages in Securities Cases’, University of Chicago Law Review, 52, 611-52.

Fisch, Jill \& Hillary Sale (2003) 'The Securities Analyst as Agent: Rethinking the Regulation of Analysts', Iowa Law Review, 88, 1035-97. 
Gigerenzer, Gerd \& Richard Selten (eds) (2001) Bounded Rationality: The Adaptive Toolbox, Cambridge: MIT Press.

Goel, Anand \& Anjan Thakor (2008) ‘Overconfidence, CEO Selection and Corporate Governance', Journal of Finance, 63, 2737-84.

Heath, Chip (1998) ‘Cognitive Repairs: How Organizational Practices can Compensate for Individual Shortcomings', Research in Organizational Behavior, 20, 1-37.

Hill, Claire \& Brett McDonnell (2007) 'Disney, Good Faith and Structural Bias', Journal of Corporation Law, 32, 833-64.

Hill, Claire \& Erin O’Hara (2007) ‘A Cognitive Theory of Trust’, Washington University Law Quarterly, 84, 1717-96.

Koch, Christopher \& C. Schmidt (2010) 'Disclosing Conflicts of Interest - Do Experience and Reputation Matter?', Accounting, Organizations and Society, 35, 95-107.

Kraakman, Reinier (1988) ‘Taking Discounts Seriously: The Implications of Discounted Share Prices as an Acquisition Motive', Columbia Law Review, 88, 891-941. 
Kreps, David (1990) ‘Corporate Culture and Economic Theory’, in J. Alt \& K. Shepsle, (eds) Perspectives on Positive Political Economy, Cambridge and New York: Cambridge University Press, 90-114.

Langevoort, Donald (1997) ‘Organized Illusions: A Behavioral Theory of Why Corporations Mislead Stock Market Investors (and Cause Other Social Harms)', University of Pennsylvania Law Review, 146, 101-72.

Langevoort, Donald (2001) 'The Human Nature of Corporate Boards: Law, Norms and the Unintended Consequences of Independence and Accountability', Georgetown Law Journal, 89, 797-832.

Langevoort, Donald (2002) 'Taming the Animal Spirits of the Stock Markets: A Behavioral Approach to Securities Regulation', Northwestern University Law Review, 97, $135-88$.

Langevoort, Donald (2004) 'Resetting the Corporate Thermostat: Lessons for Law from the Recent Financial Scandals About Self-Deception, Deceiving Others and the Design of Internal Controls', Georgetown Law Journal, 93, 285-317.

Langevoort, Donald (2006) 'Opening the Black Box of "Corporate Culture” in Law and Economics', Journal of Institutional and Theoretical Economics, 162, 80-96. 
Langevoort, Donald (2009) 'Basic at Twenty: Rethinking Fraud on the Market', Wisconsin Law Review, 2009, 151-98.

Macey, Jonathan, Geoffrey Miller, Mark Mitchell \& Jeffry Netter (1991) ‘Lessons from Financial Economics: Materiality, Reliance and Extending the Reach of Basic v. Levinson’, Virginia Law Review, 77, 1017-49.

Malmendier, Ulrike \& Geoffrey Tate (2008a) ‘CEO Overconfidence and Corporate Investment', Journal of Finance, 60, 2661-2700.

Malmendier, Ulrike \& Geoffrey Tate (2008b) ‘Who Makes Acquisitions? CEO Overconfidence and the Market's Reaction', Journal of Financial Economics, 89(1), 2043.

Manne, Henry G. (1966) Insider Trading and the Stock Market, New York: Free Press.

Milgram, Stanley (1974) Obedience to Authority: An Experimental View, London: Tavistock Press.

Miller, Geoffrey \& Gerald Rosenfeld (2009) ‘Intellectual Hazard: How Conceptual Biases in Complex Organizations Contributed to the Crisis of 2008', Harvard Journal of Law and Public Policy, 33, 807-31. 
Morck, Randall (2008) ‘Behavioral Finance in Corporate Governance: Economics and Ethics of the Devil's Advocate', Journal of Management and Governance, 12, 179-200.

O’Connor, Marleen (2003) ‘The Enron Board: The Perils of Groupthink’, University of Cincinnati Law Review, 71 1233-1319.

Posner, Richard (1998) 'Rational Choice, Behavioral Economics and the Law', Stanford Law Review, 50, 1551-75.

Posner, Richard (2009) ‘Shorting Reason’, The New Republic, April 15, 30-33.

Romano, Roberta (1986) ‘A Comment on Information Overload, Cognitive Illusions and their Implications for Public Policy’, Southern California Law Review, 59, 313-28.

Stout, Lynn (2003) 'The Mechanisms of Market Inefficiency: An Introduction to the New Finance', Journal of Corporation Law, 28, 635-69.

Weick, Karl (1995) Sensemaking in Organizations, Thousand Oaks: SAGE Publications. 